\title{
Correction to: Numerical Modelling of Water Flow Through Granular Material for Isolated and Simultaneous Extractions in Block Caving
}

\author{
Katherine Sánchez ${ }^{1,2} \cdot$ Sergio Palma ${ }^{1,3,4}\left(\mathbb{0} \cdot\right.$ Raúl L. Castro ${ }^{1,2}$ \\ Published online: 23 July 2019 \\ C) Springer-Verlag GmbH Austria, part of Springer Nature 2019

\section{Correction to: Rock Mechanics and Rock Engineering (2019) 52:133-147 \\ https://doi.org/10.1007/s00603-018-1587-x} \\ Unfortunately, the original article is published with a typing \\ error, the equation $\mathrm{d} y / \mathrm{d} x=y / x-x_{0}$ on line 850 , page 5 , is \\ incorrect. The correct equation is $\mathrm{d} x / \mathrm{d} y=x / 2 y$.
}

Publisher's Note Springer Nature remains neutral with regard to jurisdictional claims in published maps and institutional affiliations.

The original article can be found online at https://doi.org/10.1007/ s00603-018-1587-x.

Sergio Palma

sergio.palma.m@gmail.com

1 Advanced Mining Technology Center, University of Chile,

Santiago, Chile

2 Block Caving Laboratory, Department of Mining

Engineering, University of Chile, Santiago, Chile

3 School of Civil Engineering, The University of Queensland, Brisbane, Australia

4 Aix-Marseille Université, CNRS, IUSTI, Marseille, France 